Article

\title{
Preparative Separation and Purification of Trichothecene Mycotoxins from the Marine Fungus Fusarium sp. LS68 by High-Speed Countercurrent Chromatography in Stepwise Elution Mode
}

\author{
Yong Liu ${ }^{1}$, Xuezhen Zhou ${ }^{1}$, C. Benjamin Naman ${ }^{1,2,3}$ (i) , Yanbin Lu ${ }^{4}$, Lijian Ding ${ }^{1,2, *(1)}$ and \\ Shan $\mathrm{He}^{1,2, *(1)}$ \\ 1 Li Dak Sum Yip Yio Chin Kenneth Li Marine Biopharmaceutical Research Center, Ningbo University, \\ Ningbo 315211, China; 18892618896@163.com (Y.L.); zhouxuezhen@nbu.edu.cn (X.Z.); \\ bnaman@gmail.com (C.B.N.) \\ 2 Key Laboratory of Marine Biotechnology of Zhejiang Province, Ningbo University, Ningbo 315211, \\ Zhejiang, China \\ 3 Center for Marine Biotechnology and Biomedicine, Scripps Institution of Oceanography and Skaggs School \\ of Pharmacy and Pharmaceutical Sciences, University of California, San Diego, La Jolla, CA 92093, USA \\ 4 Institute of Seafood, Zhejiang Gongshang University, Hangzhou 310012, China; luyanbin@zjgsu.edu.cn \\ * Correspondences: dinglijian@nbu.edu.cn (L.D.); heshan@nbu.edu.cn (S.H.); Tel.: +86-574-8760-0458 (S.H.)
}

Received: 16 January 2018; Accepted: 16 February 2018; Published: 24 February 2018

\begin{abstract}
The contamination of foods and animal feeds with trichothecene mycotoxins is a growing concern for human and animal health. As such, large quantities of pure trichothecene mycotoxins are necessary for food safety monitoring and toxicological research. A new and effective method for the purification of trichothecene mycotoxins from a marine fungus, Fusarium sp. LS68, is described herein. Preparative high-speed countercurrent chromatography (HSCCC) was utilized for the scalable isolation and purification of four trichothecene mycotoxins for the first time in stepwise elution mode, with a biphasic solvent system composed of hexanes-EtOAc- $\mathrm{CH}_{3} \mathrm{OH}-\mathrm{H}_{2} \mathrm{O}(6: 4: 5: 5, v / v / v / v)$ and (8.5:1.5:5:5, $v / v / v / v)$. This preparative HSCCC separation was performed on $200 \mathrm{mg}$ of crude sample to yield four trichothecene mycotoxins, roridin E (1), roridin E acetate (2), verrucarin L acetate (3), and verrucarin J (4) in a single run, with each of $>98 \%$ purity. These compounds were identified by MS, ${ }^{1} \mathrm{H}$ NMR, ${ }^{13} \mathrm{C}$ NMR, and polarimetry. The results demonstrate an efficient HSCCC method for the separation of trichothecene mycotoxins, which can be utilized to produce pure commercial and research standards.
\end{abstract}

Keywords: trichothecene mycotoxins; roridin; verrucarin; high-speed countercurrent chromatography; preparative separation; stepwise elution

\section{Introduction}

According to the Food and Agriculture Organization of the United Nations, about 25\% of the food crops in the world are contaminated with mycotoxins, and these have adverse effects on humans, animals, and crops that result in serious illnesses and economic losses [1]. Among the major mycotoxins produced by Fusarium species, trichothecenes are pathogenic to important agricultural crops and foods [2], and these lead to serious economic losses by reducing yields and overall quality of North American agricultural products [3,4]. For example, Fusarium head blight disease, caused by trichothecene mycotoxins, has been shown to have contaminated cereals and grains $[5,6]$.

Trichothecenes are a group of tetracyclic sesquiterpene mycotoxins that are produced by various fungi from the order Hypocreales, including those of the genera Fusarium, Myrothecium, 
Verticimonosporium, Stachybotrys, Trichoderma, Trichothecium, Cephalosporium, and Cylindrocarpon [7-11]. These molecules are potent phytotoxins, and act as the virulence factors of pathogenic fungi on sensitive infected host plants, particularly wheat and barley [12-14]. The unfortunate contamination of botanical dietary supplements with mycotoxins has also been reported recently, representing a significant risk to public health [15]. One obstacle to the further investigation of these important topics has been the scarce quantity of pure compounds from the trichothecene class. Therefore, the preparative separation of high purity trichothecene mycotoxins is of great interest. At present, trichothecene mycotoxins are isolated from fungal extracts by conventional methods, such as macroporous resin separation followed by silica gel column chromatography. These methods can be considered costly, laborious, and time-consuming, and furthermore result in substantial sample loss due to irreversible adsorption to the silica [16,17]. It is therefore important to develop rapid and efficient methods for the separation and purification of trichothecene mycotoxins.

High-speed countercurrent chromatography (HSCCC) is a technique that uses liquid-liquid partition chromatography to improve recovery rates and efficiency, and which eliminates irreversible adsorption by solid support media [17-19]. HSCCC has been widely used for the preparative separation and purification of natural products, and this is a scalable technology [20,21]. Disclosed herein is the first preparative isolation and purification of trichothecene mycotoxins by HSCCC in stepwise elution mode, allowing for the purification of several compounds in one run. The trichothecene mycotoxins roridin E (1), roridin E acetate (2), verrucarin L acetate (3), and verrucarin J (4) were thus isolated from an epiphytic fungus, Fusarium sp. LS68, which was derived from the sponge Haliclona sp. The structures of 1-4 are presented in Figure 1.

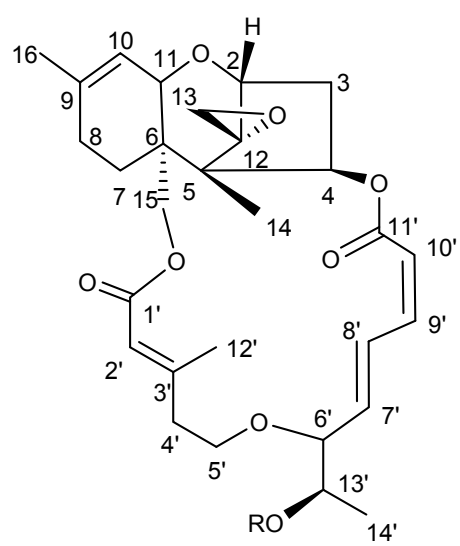

$1 \mathrm{R}=\mathrm{H}$

$2 \mathrm{R}=\mathrm{Ac}$

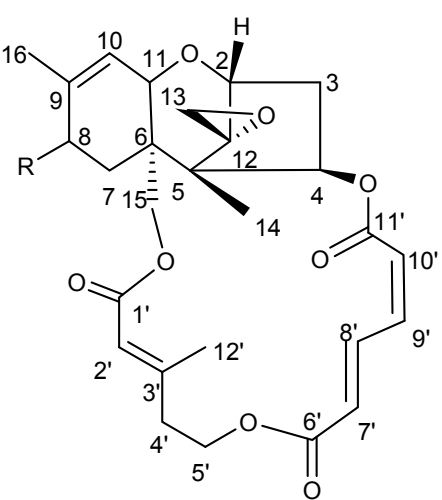

$3 \mathrm{R}=\mathrm{OAC}$

$4 \mathrm{R}=\mathrm{H}$

Figure 1. Structures of roridin E (1), roridin E acetate (2), verrucarin L acetate (3), verrucarin J (4).

\section{Results and Discussion}

\subsection{HPLC Analysis of the Crude Extract}

An HPLC method was developed to ensure the baseline separation of the target compounds and impurities. Different solvent systems, flow rates, detection wavelengths, and column temperatures were screened. The components of interest, 1-4, were satisfactorily separated by a $\mathrm{CH}_{3} \mathrm{CN} / \mathrm{H}_{2} \mathrm{O}$ gradient (flow rate $0.8 \mathrm{~mL} / \mathrm{min}, 25-75 \% \mathrm{CH}_{3} \mathrm{CN}$ from $0-60 \mathrm{~min}$ ) when the column temperature was set at $25{ }^{\circ} \mathrm{C}$. The HPLC chromatogram of the crude extract is shown in Figure 2, Panel A. The same method was used to analyze HSCCC method development samples, and later HSCCC eluents (Figure 2, Panels B-E), for fraction pooling. 


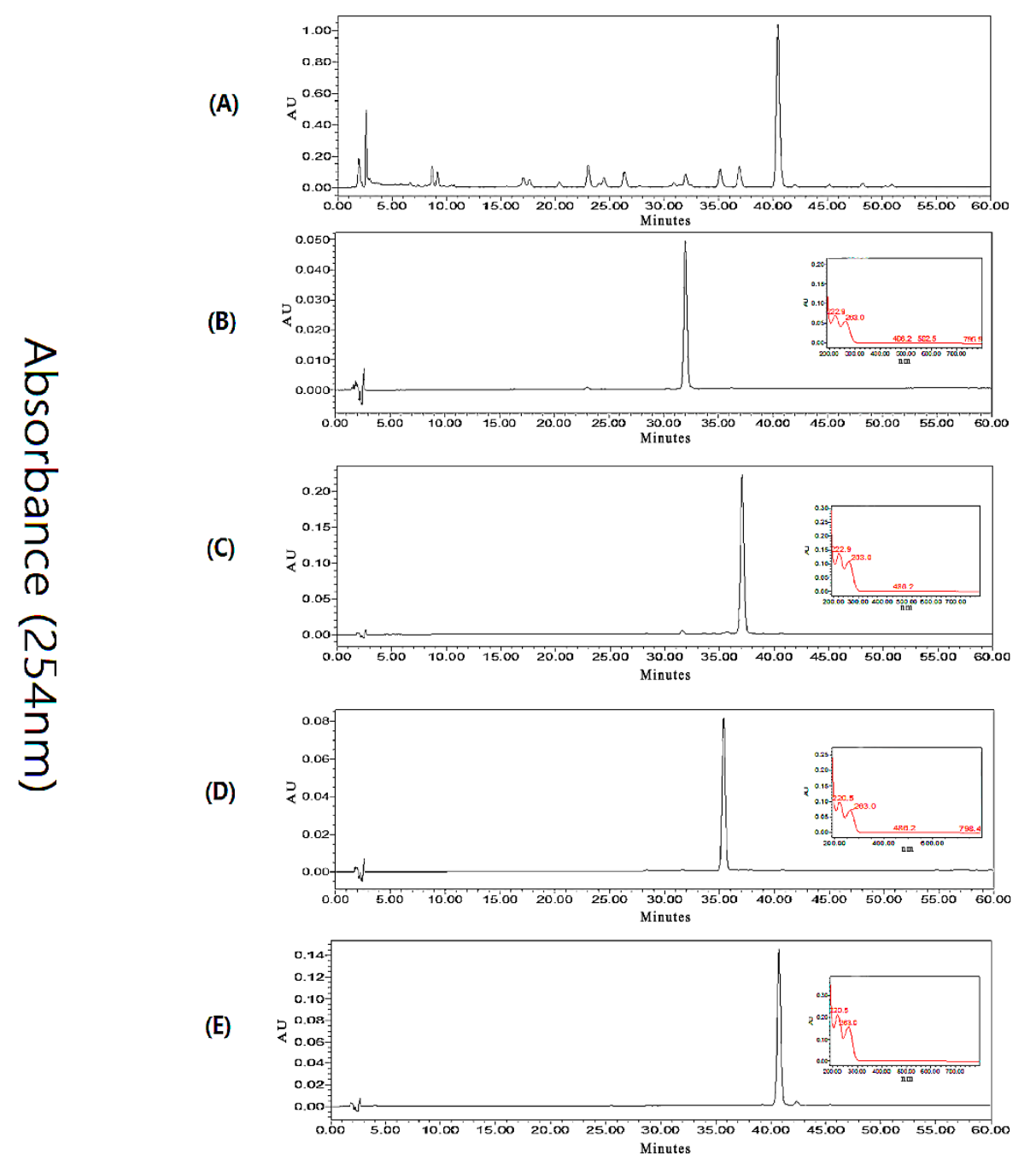

Figure 2. Representative analytical HPLC chromatograms. (A) Crude extract of Fusarium sp; (B) refined peak 1 from HSCCC, corresponding to compound 1; (C) refined peak 2 from HSCCC, corresponding to compound 3; (D) refined peak 3 from HSCCC, corresponding to compound 2; (E) refined peak 4 from HSCCC, corresponding to compound 4. For B-D, UV profiles of the major peak are inset at $254 \mathrm{~nm}$.

\subsection{Optimization of Suitable HSCCC Solvent System}

In order to efficiently separate and purify target compounds, the selection of an optimal biphasic solvent system is critical for preparative HSCCC. According to the "golden rules of HSCCC", satisfactory partition coefficient $K_{\mathrm{D}}$ values should meet some basic requirements: (1) the target compounds should each be in the range of $0.5 \leq K_{\mathrm{D}} \leq 2.0$; (2) each set of two target compounds should have the separation factor $\alpha>1.5$, where $\alpha$ is the ratio of the two $K_{D}$ values $\left(\alpha=K_{D}{ }^{1} / K_{D}{ }^{2}\right.$, for $K_{\mathrm{D}}^{1}>K_{\mathrm{D}}^{2}$ ); and (3) higher retention of the stationary phase will provide better peak resolution [22]. Thus, preliminary studies were carried out to examine the $K_{\mathrm{D}}$ values of the trichothecene mycotoxins 1-4 in different hexanes-EtOAc- $\mathrm{CH}_{3} \mathrm{OH}-\mathrm{H}_{2} \mathrm{O}$ solvent systems of different volume ratios by liquid-liquid partitioning and HPLC analysis. The $K_{\mathrm{D}}$ values for $\mathbf{1 - 4}$ in the various solvent systems tested are shown in Table 1. 
Table 1. Partition coefficients $\left(K_{\mathrm{D}}\right)$ of compounds 1-4 in several hexanes-EtOAc- $\mathrm{CH}_{3} \mathrm{OH}-\mathrm{H}_{2} \mathrm{O}$ solvent systems tested for high-speed countercurrent chromatography (HSCCC) separation.

\begin{tabular}{|c|c|c|c|c|}
\hline \multirow{2}{*}{$\begin{array}{l}\text { Solvent System }(v / v) \\
\text { Hexanes-EtOAc- } \mathrm{CH}_{3} \mathrm{OH}-\mathrm{H}_{2} \mathrm{O}\end{array}$} & \multicolumn{4}{|c|}{$K_{\mathrm{D}}$} \\
\hline & Compound 1 & Compound 2 & Compound 3 & Compound 4 \\
\hline 1:1:1:1 & 2.08 & 2.61 & 2.33 & 10.58 \\
\hline $5.5: 4.5: 5: 5$ & 0.93 & 2.25 & 2.14 & 4.73 \\
\hline $6: 4: 5: 5$ & 0.61 & 1.83 & 1.26 & 3.32 \\
\hline $6.5: 3.5: 5: 5$ & 0.37 & 1.43 & 1.12 & 2.58 \\
\hline 7:3:5:5 & 0.45 & 1.25 & 0.80 & 3.21 \\
\hline $7.5: 2.5: 5: 5$ & 0.36 & 1.10 & 0.68 & 2.73 \\
\hline $8: 2: 5: 5$ & 0.19 & 0.58 & 0.54 & 1.87 \\
\hline $8.5: 1.5: 5: 5$ & 0.11 & 0.37 & 0.32 & 1.12 \\
\hline 9:1:5:5 & 0.10 & 0.30 & 0.25 & 0.83 \\
\hline
\end{tabular}

No single suitable biphasic solvent system was found that had $K_{\mathrm{D}}$ values between 0.5 and 2 for each of compounds 1-4 at the same time. To overcome this challenge, a stepwise HSCCC elution mode was chosen in order to separate compounds with significantly different $K_{\mathrm{D}}$ values in a single run. This technique had been successfully applied previously by some research groups $[23,24]$.

The use of the "HeMWat", or hexanes-EtOAc- $\mathrm{CH}_{3} \mathrm{OH}-\mathrm{H}_{2} \mathrm{O}$, solvent system at volumetric ratios of 1:1:1:1 and 5.5:4.5:5:5 both afforded larger $K_{\mathrm{D}}$ values unsuitable for the separation of the trichothecene mycotoxins investigated. However, the biphasic solvent system of hexanes-EtOAc- $\mathrm{CH}_{3} \mathrm{OH}-\mathrm{H}_{2} \mathrm{O}$ at a volumetric ratio of 6.5:3.5:5:5 yielded acceptable $K_{\mathrm{D}}$ values of compounds 1-3 between 0.5 and 2, although compounds 2 and 3 had an unsuitable separation factor $\alpha<1.5$. However, the biphasic hexanes-EtOAc- $\mathrm{CH}_{3} \mathrm{OH}-\mathrm{H}_{2} \mathrm{O}$ solvent system at a volume ratio of 6:4:5:5 led to the observation of the $K_{\mathrm{D}}$ values between 0.5 and 2 for compounds 1,2 , and 3 , and each pair had a separation factor $\alpha>1.5$. Nevertheless, this solvent system offered an unsuitable $K_{D}$ value (2.58) for compound 4 . To overcome this problem, the hexanes-EtOAc- $\mathrm{CH}_{3} \mathrm{OH}-\mathrm{H}_{2} \mathrm{O}$ 8.5:1.5:5:5 solvent system was selected for the second part of the HSCCC run, since it produced a suitable $K_{\mathrm{D}}$ value of 1.12 for compound 4 , and it would only be used in stepwise mode after the elution of 1-3.

\subsection{Stepwise HSCCC Separation}

The optimized stepwise elution method was applied for the direct preparative HSCCC separation of $200 \mathrm{mg}$ of crude Fusarium extract in a single run. As shown in Figure 3, the separation initiated with the solvent system of hexanes-EtOAc- $\mathrm{CH}_{3} \mathrm{OH}-\mathrm{H}_{2} \mathrm{O}$ 6:4:5:5, and the upper phase was used as the stationary phase while the lower phase was used as the mobile phase in the head-to-tail elution mode. Retention of the stationary phase was 63\%, and after peaks 1-3 eluted at 102, 180, and $205 \mathrm{~min}$, respectively, the mobile phase was switched to the lower phase of the solvent system (8.5:1.5:5:5) at $250 \mathrm{~min}$. Peak 4 was well resolved, and eluted at $350 \mathrm{~min}$. Timewise fractions were collected from the HSCCC separation and pooled after evaluation by HPLC, to yield compound $\mathbf{1}$ (11.3 $\mathrm{mg}$ ), compound $\mathbf{2}$ $(7.7 \mathrm{mg})$, compound $3(4.7 \mathrm{mg})$, and compound $4(21.3 \mathrm{mg})$. Each compound isolated had a purity of $>98 \%$ based on UV peak integrations (Figure 2, Panels B-E). The chromatogram of HSCCC separation is shown in Figure 3. 


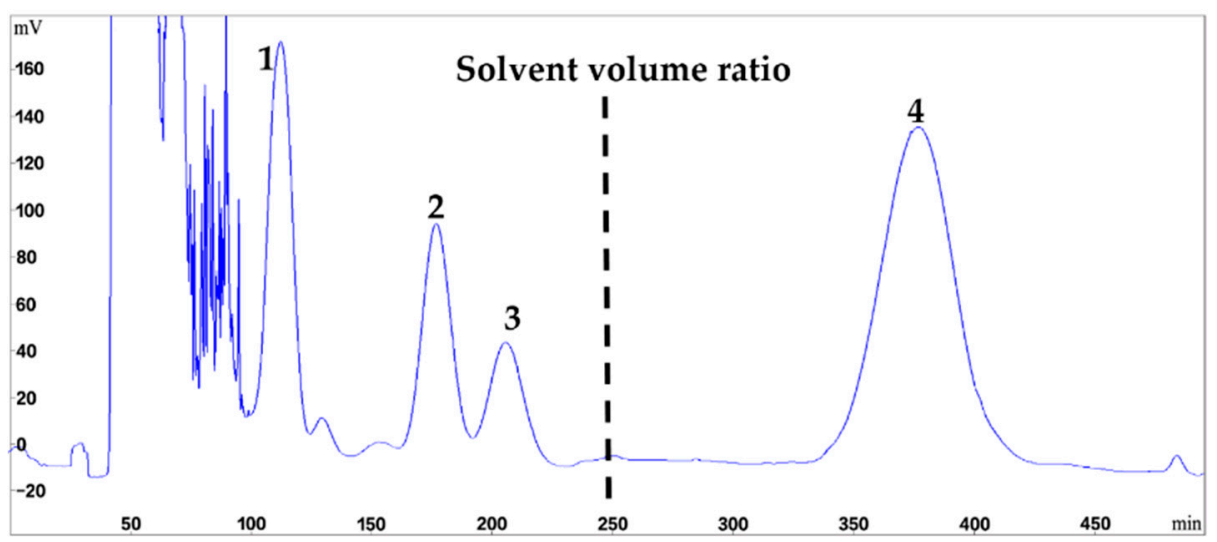

Figure 3. HSCCC chromatogram of the crude extract from Fusarium sp. LS68 using stepwise elution with solvent systems A and B. The dotted line represents the time at which the solvent system was switched from A to B. Solvent system A: hexanes-EtOAc- $\mathrm{CH}_{3} \mathrm{OH}-\mathrm{H}_{2} \mathrm{O}(6: 4: 5: 5, v / v / v / v)$, solvent system B: hexanes-EtOAc- $\mathrm{CH}_{3} \mathrm{OH}-\mathrm{H}_{2} \mathrm{O}(8.5: 1.5: 5: 5, v / v / v / v)$; stationary phase: upper phase of solvent system A; mobile phase: lower aqueous phase of solvent system A and B; column capacity, $350 \mathrm{~mL}$; rotation speed, $800 \mathrm{rpm}$; column temperature, $25^{\circ} \mathrm{C}$; flow rate, $2.0 \mathrm{~mL} / \mathrm{min}$; detection, $254 \mathrm{~nm}$; sample injected, $200 \mathrm{mg}$ in $6 \mathrm{~mL}$ biphasic solution; retention of the stationary phase, $63 \%$; peak identification: roridin E (1), roridin E acetate (2), verrucarin L acetate (3), verrucarin J (4).

\subsection{Structural Identification}

The structural identification of 1-4 was conducted by HRESI-MS, ${ }^{1} \mathrm{H}$ and ${ }^{13} \mathrm{C}$ NMR analyses, as well as specific rotation data, and these were compared with literature values. Accordingly, the molecules isolated were identified as roridin E (1) [25], roridin E acetate (2) [26], verrucarin L acetate (3) [27], and verrucarin J (4) [27] (see Supplementary Materials).

\section{Materials and Methods}

\subsection{Reagents and Materials}

All solvents used for HSCCC were of analytical grade (Huadong Chemicals, Hangzhou, China). Reverse osmosis Milli-Q water (18 M) (Millipore, Bedford, MA, USA) was used for all solutions and dilutions. Methanol used for HPLC analyses was of chromatographic grade and purchased from Anpel Laboratory Technologies (Shanghai, China). The $\mathrm{CDCl}_{3}$ used for NMR analyses was purchased from Tenglong Weibo Technology (Qingdao, China).

\subsection{Fungal Material}

The marine fungi Fusarium sp. LS68, was isolated and cultured from a Halicloma sp. sponge collected from Linshui, Hainan Province, China. It was identified as Fusarium sp. according to the morphological and molecular (ITS rDNA sequence) analyses (GenBank accession number EU860057, $99 \%$ similarity). A voucher specimen was deposited at the School of Marine Sciences, Ningbo University (Ningbo, China).

\subsection{Apparatus}

HSCCC was carried out using a model TBE-300C high-speed countercurrent chromatograph (Tauto Biotech Co. Ltd., Shanghai, China), containing a self-balancing three-coil centrifuge rotor equipped with three preparative multilayer coils and a total capacity of $320 \mathrm{~mL}$. The internal diameter of PTFE (Polytetrafluoroethylene) tubing was $1.9 \mathrm{~mm}$. The apparatus maximum rotational speed is $1000 \mathrm{rpm}$ and has a $20 \mathrm{~mL}$ manual sample loop. The revolution radius was $5 \mathrm{~cm}$ and the $\beta$ value of the multilayer coil varied from 0.5 at the internal terminal to 0.8 at the external terminal. 
An integrated TBP 5002 (Tauto Biotech Co. Ltd.) was used to pump the two-phase HSCCC solvent system, and the UV absorbance of the effluent was measured at $254 \mathrm{~nm}$ by a UV 1001 detector (Shanghai Sanotac Scientific Instruments Co. Ltd., Shanghai, China). A DC-0506 constant temperature regulator (Tauto Biotech Co. Ltd.) was used to control the temperature during HSCCC. An N2000 data analysis system (Institute of Automation Engineering, Zhejiang University, Hangzhou, China) was employed for HSCCC data collection and analysis. The analytical HPLC equipment was an Alliance 2695 equipped with a model 2998 diode array detector and Empower System (Waters Co., Milford, MA, USA). NMR experiments were carried out using a DirectDrive2 $600 \mathrm{MHz}$ NMR spectrometer (Agilent, Santa Clara, CA, USA) at $25^{\circ} \mathrm{C}$ and Auto Triple Resonance (Agilent, Santa Clara, CA, USA). HRESIMS data were measured using a Waters Q-TOF Premier LC/MS spectrometer (Waters Co., Milford, MA, USA). Column chromatography was conducted with silica gel (200-300 mesh, Qingdao Marine Chemical Inc. Qingdao, China). The UV spectra were recorded on an NADE Evolution 201 spectrophotometer (Waters Co., Milford, CT, USA). Optical rotations were measured on an Autopol VI (Rudolph Research Analytical, Hackettstown, NJ, USA).

\subsection{Culturing and Extraction}

The fungus Fusarium sp. LS68 was cultivated in a seawater-based potato dextrose broth (PDB) medium and incubated on a rotary shaker at $150 \mathrm{rpm}$ and $25^{\circ} \mathrm{C}$ for 14 days. The fermentation broth $(30 \mathrm{~L})$ was extracted with EtOAc $(3 \times 30 \mathrm{~L})$. The organic solvent partitions were combined and evaporated under reduced pressure at $40{ }^{\circ} \mathrm{C}$ to yield a crude extract $(30 \mathrm{~g})$. This sample was stored in a refrigerator at $4{ }^{\circ} \mathrm{C}$ until the subsequent HSCCC separation.

\subsection{Determination of Partition Coefficients $\left(K_{D}\right)$}

In order to determine the appropriate solvent systems for optimal partition coefficients $\left(K_{\mathrm{D}}\right)$, various solvent combinations of hexanes-EtOAc- $\mathrm{CH}_{3} \mathrm{OH}-\mathrm{H}_{2} \mathrm{O}$ were attempted. A 2-mg sample of crude extract was added to a $10 \mathrm{~mL}$ test tube along with $8 \mathrm{~mL}$ of an experimental biphasic solvent system. The test tube was then capped and shaken vigorously for $3 \mathrm{~min}$, to allow the distribution of the extract between the two phases. After reaching equilibration, equal aliquots of each phase $(10 \mu \mathrm{L})$ were analyzed by HPLC-DAD to determine the partition coefficient $\left(K_{\mathrm{D}}\right)$ of each target compound. The $K_{\mathrm{D}}$ values were defined as the integrated peak area of each target compound in the upper phase divided by that in the lower phase, as observed at $254 \mathrm{~nm}$.

\subsection{HSCCC Separation}

The biphasic solvent systems of hexanes-EtOAc- $-\mathrm{CH}_{3} \mathrm{OH}-\mathrm{H}_{2} \mathrm{O}$ (6:4:5:5 and 8.5:1.5:5:5) were selected for the HSCCC separation. A $200 \mathrm{mg}$ sample of crude extract was dissolved in $6 \mathrm{~mL}$ of each phase of a solvent mixture consisting of equal volumes of both upper and lower phases for preparative HSCCC separation. In the single run, the upper (stationary) phase was pumped into and filled the coil column of TBE-300C ( $320 \mathrm{~mL}$, Tauto Biotech Co. Ltd., Shanghai, China) by a constant flow at $10.0 \mathrm{~mL} / \mathrm{min}$. The column was then rotated at a speed of $800 \mathrm{rpm}$, and the lower (mobile) phase was pumped into the column in the "head to tail" elution mode at $2.0 \mathrm{~mL} / \mathrm{min}$. When the mobile phase began to elute at the tail outlet, the hydrodynamic equilibrium state of the two phases was established. Subsequently, the sample solution $(6 \mathrm{~mL})$ containing $200 \mathrm{mg}$ of crude extract was injected through the sample port. After $250 \mathrm{~min}$, the pump was stopped and then the lower phase of hexanes-EtOAc- $\mathrm{CH}_{3} \mathrm{OH}-\mathrm{H}_{2} \mathrm{O}$ (8.5:1.5:5:5) was pumped into the column as the new mobile phase at $2.0 \mathrm{~mL} / \mathrm{min}$. The separation temperature was controlled at $25^{\circ} \mathrm{C}$. The effluent was continuously monitored with a UV detector (Shanghai Sanotac Scientific Instruments Co. Ltd., Shanghai, China) at $254 \mathrm{~nm}$. After the separation procedure, the solvents in the column were completely eluted and collected. Fractions were collected near $110 \mathrm{~min}, 180 \mathrm{~min}, 210 \mathrm{~min}$, and $380 \mathrm{~min}$, respectively, and analyzed by HPLC to allow for fraction pooling. 


\subsection{HPLC Analysis and Identification of the Peaks}

Each fraction generated by preparative HSCCC was evaluated by HPLC, using a $150 \mathrm{~mm} \times 4.6 \mathrm{~mm}$ i.d., $5 \mu \mathrm{m}$, YMC-Pack ODS-A column (Waters Co., Milford, CT, USA) that was maintained at $25^{\circ} \mathrm{C}$. The samples were separated with a $\mathrm{CH}_{3} \mathrm{CN} / \mathrm{H}_{2} \mathrm{O}$ gradient (flow rate $0.8 \mathrm{~mL} / \mathrm{min}, 25-75 \% \mathrm{CH}_{3} \mathrm{CN}$ from 0-60 min). The effluent was continuously monitored by a UV detector at $220 \mathrm{~nm}$ and $254 \mathrm{~nm}$. Fractions that showed only one peak in the chromatogram were respectively pooled together to yield compounds 1 (11.3 mg, the $\left.t_{\mathrm{R}}(\mathrm{HPLC}) 32 \mathrm{~min}, t_{\mathrm{R}}(\mathrm{HSCCC}) 102-120 \mathrm{~min}\right), 2$ (7.7 mg, $t_{\mathrm{R}}(\mathrm{HPLC})$ $37 \mathrm{~min}, t_{\mathrm{R}}$ (HSCCC) 180-195 min), 3 (4.7 mg, $t_{\mathrm{R}}$ (HPLC) $35 \mathrm{~min}, t_{\mathrm{R}}$ (HSCCC) 205-220 min), and 4 (21.3 mg, $t_{\mathrm{R}}$ (HPLC) $40 \mathrm{~min}, t_{\mathrm{R}}$ (HSCCC) 350-400 min). Compounds 1-4 were identified as roridin $\mathrm{E}$ (1) [25], roridin E acetate (2) [26], verrucarin L acetate (3) [27], and verrucarin J (4) [27] by comparison of their UV, ${ }^{1} \mathrm{H}$ and ${ }^{13} \mathrm{C}$ NMR, and specific rotation data with literature values. The purity levels of these samples were determined by peak area percentage after the automated integration of each chromatogram.

\section{Conclusions}

Trichothecenes are worldwide plant toxins that cause enormous yield losses in major economic crops. Some researchers have highlighted the need to decontaminate mycotoxins in foods and feeds [28]. However, investigations of trichothecene phytotoxicity are limited due to the difficulty and expense of obtaining trichothecene mycotoxins in high purity and sufficient quantity. In this study, the first efficient preparative separation of four trichothecene mycotoxins from the marine fungi Fusarium sp. LS68 by a stepwise HSCCC elution method was developed. The purities of the trichothecene mycotoxins isolated, 1-4, were $>98 \%$. Therefore, the stepwise HSCCC method is an efficient technique for the isolation of high purity trichothecene mycotoxins. This method is industrially scalable with the size of the HSCCC instrumentation, and may provide a means to obtain pure trichothecene mycotoxins in the quantities needed for broader biological examinations and the generation of analytical standards for the agricultural food, supplement, and feedstock industries.

Supplementary Materials: The following are available online at www.mdpi.com/1660-3397/16/2/73/s1, Figure S1a, ${ }^{1} \mathrm{H}$ NMR spectrum of compound $1\left(\mathrm{CDCl}_{3}, 600 \mathrm{MHz}\right)$; Figure $\mathrm{S} 1 \mathrm{~b},{ }^{13} \mathrm{C}$ NMR spectrum of compound 1 $\left(\mathrm{CDCl}_{3}, 150 \mathrm{MHz}\right)$; Figure S1c, HRESIMS spectrum of compound 1; Figure S1d, UV spectrum of compound 1; Figure S2a, ${ }^{1} \mathrm{H}$ NMR spectrum of compound $2\left(\mathrm{CDCl}_{3}, 600 \mathrm{MHz}\right)$; Figure S2b, ${ }^{13} \mathrm{C}$ NMR spectrum of compound 2 $\left(\mathrm{CDCl}_{3}, 150 \mathrm{MHz}\right)$; Figure S2c, HRESIMS spectrum of compound 2; Figure S2d, UV spectrum of compound 2; Figure S3a, ${ }^{1} \mathrm{H}$ NMR spectrum of compound $3\left(\mathrm{CDCl}_{3}, 600 \mathrm{MHz}\right)$; Figure $\mathrm{S} 3 \mathrm{~b},{ }^{13} \mathrm{CNMR}$ spectrum of compound 3 $\left(\mathrm{CDCl}_{3}, 150 \mathrm{MHz}\right)$; Figure S3c, HRESIMS spectrum of compound 3; Figure S3d, UV spectrum of compound 3; Figure $\mathrm{S} 4 \mathrm{a},{ }^{1} \mathrm{H}$ NMR spectrum of compound $4\left(\mathrm{CDCl}_{3}, 600 \mathrm{MHz}\right)$; Figure $\mathrm{S} 4 \mathrm{~b},{ }^{13} \mathrm{CNMR}$ spectrum of compound $4\left(\mathrm{CDCl}_{3}, 150 \mathrm{MHz}\right)$; Figure S4c, HRESIMS spectrum of compound 4; Figure S4d, UV spectrum of compound 4; Table S1, NMR data of compound 1 in $\mathrm{CDCl}_{3}$; Table S2, NMR data of compound 2 in $\mathrm{CDCl}_{3}$; Table S3, NMR data of compound 3 in $\mathrm{CDCl}_{3}$; Table S4, NMR data of compound 4 in $\mathrm{CDCl}_{3}$; Table S5, Specific rotation values of compounds 1-4; Table S6, UV values of compounds 1-4.

Acknowledgments: This study was supported by the National Natural Science Foundation of China (41776168, 41706167), the Natural Science Foundation of Zhejiang Province (LY15C200004), Scientific Research Fund of Zhejiang Provincial Education Department (Y201737271), Ningbo Sci. \& Tech. Projects for Common Wealth (2015C10026, 2017C10016), the National 111 Project of China, the Li Dak Sum Yip Yio Chin Kenneth Li Marine Biopharmaceutical Development Fund, and the K.C. Wong Magna Fund in Ningbo University.

Author Contributions: Conceived and designed the experiments: Lijian Ding, Shan He. Collect the samples: Shan He, Yong Liu, Yanbin Lu. Performed the experiments: Yong Liu, Xuezhen Zhou. Analyzed the data: Yong Liu, Lijian Ding. Wrote the paper: Yong Liu, C. Benjamin Naman, Lijian Ding.

Conflicts of Interest: The authors declare no conflict of interest.

\section{References}

1. Cast, I. Mycotoxins: Risks in Plant, Animal, And Human Systems; Task Force Report No. 139; Council for Agriculture Science and Technology: Ames, IA, USA, 2003. 
2. Berthiller, F.; Crews, C.; Dall'Asta, C.; Saeger, S.D.; Haesaert, G.; Karlovsky, P.; Oswald, I.P.; Seefelder, W.; Speijers, G.; Stroka, J. Masked mycotoxins: A review. Mol. Nutr. Food Res. 2013, 57, 165-186. [CrossRef] [PubMed]

3. McMullen, M.; Jones, R.; Gallenberg, D. Scab of wheat and barley: A re-emerging disease of devastating impact. Plant Dis. 1997, 81, 1340-1348. [CrossRef]

4. Goswami, R.S.; Kistler, H.C. Heading for disaster: Fusarium graminearum on cereal crops. Mol. Plant Pathol. 2004, 5, 515-525. [CrossRef] [PubMed]

5. Starkey, D.E.; Ward, T.J.; Aoki, T.; Gale, L.R.; Kistler, H.C.; Geiser, D.M.; Suga, H.; Tóth, B.; Varga, J.; O'Donnell, K. Global molecular surveillance reveals novel fusarium head blight species and trichothecene toxin diversity. Fungal Genet. Biol. 2007, 44, 1191-1204. [CrossRef] [PubMed]

6. Kazan, K.; Gardiner, D.M.; Manners, J.M. On the trail of a cereal killer: Recent advances in Fusarium graminearum pathogenomics and host resistance. Mol. Plant Pathol. 2012, 13, 399-413. [CrossRef] [PubMed]

7. Grove, J.F. Macrocyclic trichothecenes. Nat. Prod. Rep. 1993, 10, 429-448. [CrossRef]

8. Grove, J.F. The trichothecenes and their biosynthesis. Prog. Chem. Org. Nat. Prod. 2007, 38, 63-130. [CrossRef]

9. Wilkins, K.; Nielsen, K.F.; Din, S.U. Patterns of volatile metabolites and nonvolatile trichothecenes produced by isolates of Stachybotrys, Fusarium, Trichoderma, Trichothecium and Memnoniella. Environ. Sci. Pollut. Res. 2003, 10, 162-166. [CrossRef]

10. Trapp, S.; Hohn, T.; McCormick, S.; Jarvis, B. Characterization of the gene cluster for biosynthesis of macrocyclic trichothecenes in Myrothecium roridum. Mol. Gen. Genet. 1998, 257, 421-432. [CrossRef] [PubMed]

11. Jarvis, B.B.; Mazzola, E.P. Macrocyclic and other novel trichothecenes: Their structure, synthesis, and biological significance. Acc. Chem. Res. 1982, 15, 388-395. [CrossRef]

12. Desjardins, A.E.; Mccormick, S.P.; Appell, M. Structure-activity relationships of trichothecene toxins in an Arabidopsis thaliana leaf assay. J. Agric. Food Chem. 2007, 55, 6487-6492. [CrossRef] [PubMed]

13. Alexander, N.J.; McCormick, S.P.; Ziegenhorn, S.L. Phytotoxicity of selected trichothecenes using Chlamydomonas reinhardtii as a model system. Nat. Toxins 1999, 7, 265-269. [CrossRef]

14. Eudes, F.; Comeau, A.; Rioux, S.; Collin, J. Phytotoxicité de huit mycotoxines associées à la fusariose de l'épi chez le blé. Can. J. Plant Pathol. 2000, 22, 286-292. [CrossRef]

15. Veprikova, Z.; Zachariasova, M.; Dzuman, Z.; Zachariasova, A.; Fenclova, M.; Slavikova, P.; Vaclavikova, M.; Mastovska, K.; Hengst, D.; Hajslova, J. Mycotoxins in plant-based dietary supplements: Hidden health risk for consumers. J. Agric. Food Chem. 2015, 63, 6633-6643. [CrossRef] [PubMed]

16. Cutler, H.G.; Jarvis, B.B. Preliminary observations on the effects of macrocyclic trichothecenes on plant growth. Environ. Exp. Bot. 1985, 25, 115-128. [CrossRef]

17. Ryu, S.M.; Lee, H.M.; Song, E.G.; Seo, Y.H.; Lee, J.; Guo, Y.Q.; Kim, B.S.; Kim, J.J.; Jin, S.H.; Ryu, K.H. Antiviral activities of trichothecenes isolated from Trichoderma albolutescens against pepper mottle virus. J. Agric. Food Chem. 2017, 65, 4273-4279. [CrossRef] [PubMed]

18. Yang, Y.; Zhao, Y.; Gu, D.; Ayupbek, A.; Huang, Y.; Dou, J.; Ito, Y.; Zhang, T.; Aisa, H.A. Separation of the minor flavonols from flos gossypii by high-speed countercurrent chromatography. J. Liq. Chromatogr. Relat. Technol. 2010, 33, 1502-1515. [CrossRef] [PubMed]

19. Sutherland, I.A.; Fisher, D. Role of counter-current chromatography in the modernisation of chinese herbal medicines. J. Chromatogr. A 2009, 1216, 740-753. [CrossRef] [PubMed]

20. Sticher, O. Natural product isolation. Nat. Prod. Rep. 2008, 25, 517-554. [CrossRef] [PubMed]

21. Oka, F.; Oka, H.; Ito, Y. Systematic search for suitable two-phase solvent systems for high-speed counter-current chromatography. J. Chromatogr. A 1991, 538, 99-108. [CrossRef]

22. Ito, Y. Golden rules and pitfalls in selecting optimum conditions for high-speed counter-current chromatography. J. Chromatogr. A 2005, 1065, 145-168. [CrossRef] [PubMed]

23. He, S.; Wang, H.; Yan, X.; Zhu, P.; Chen, J.; Yang, R. Preparative isolation and purification of macrolactin antibiotics from marine bacterium Bacillus amyloliquefaciens using high-speed counter-current chromatography in stepwise elution mode. J. Chromatogr. A 2013, 1272, 15-19. [CrossRef] [PubMed]

24. Huang, X.Y.; Ignatova, S.; Hewitson, P.; Di, D.L. An overview of recent progress in elution mode of counter current chromatography. Trac-Trend Anal. Chem. 2016, 77, 214-225. [CrossRef]

25. Ridge, C.D.; Mazzola, E.P.; Colesb, M.P.; Hinkley, S.F.R. Isolation and characterization of roridin E. Magn. Reson. Chem. 2016, 55, 337-340. [CrossRef] [PubMed] 
26. Isaka, M.; Punya, J.; Lertwerawat, Y.; Tanticharoen, M.; Thebtaranonth, Y. Antimalarial activity of macrocyclic trichothecenes isolated from the fungus Myrothecium verrucaria. J. Nat. Prod. 1999, 62, 329-331. [CrossRef] [PubMed]

27. Namikoshi, M.; Kobayashi, H.; Yoshimoto, T.; Meguro, S.; Akano, K. Isolation and characterization of bioactive metabolites from marine-derived filamentous fungi collected from tropical and sub-tropical coral reefs. Chem. Pharm. Bull. 2000, 48, 1452-1457. [CrossRef] [PubMed]

28. Temba, B.A.; Sultanbawa, Y.; Kriticos, D.J.; Fox, G.P.; Harvey, J.J.; Fletcher, M.T. Tools for defusing a major global food and feed safety risk: Nonbiological postharvest procedures to decontaminate mycotoxins in foods and feeds. J. Agric. Food Chem. 2016, 64, 8959-8972. [CrossRef] [PubMed]

2018 by the authors. Licensee MDPI, Basel, Switzerland. This article is an open access article distributed under the terms and conditions of the Creative Commons Attribution (CC BY) license (http://creativecommons.org/licenses/by/4.0/). 